\title{
Children undergoing anaesthesia: what are the rights of the child?
}

Kristian Noerholm Jensen ${ }^{1, \dagger, *}$, Tom Giedsing Hansen $n^{1,2, \uparrow}$

\author{
${ }^{1}$ Department of Anesthesiology and \\ Intensive Care, Odense University \\ Hospital, Odense, Denmark \\ ${ }^{2}$ Department of Clinical Research, \\ University of Southern Denmark, \\ Odense, Denmark

\section{*Correspondence} \\ Kristian.Noerholm.Jensen@rsyd.dk \\ (Kristian Noerholm Jensen) \\ $\dagger$ These authors contributed equally.
}

\begin{abstract}
The United Nations Convention on the Rights of the Child (UNCRC) outlines the rights of the child and is the grounds on how we care for children in healthcare institutions. Anesthesiologists are obliged to respect the child's rights when undertaking pediatric anesthesia. The Safe Anesthesia for every tot initiative (SAFETOTS) has translated the UNCRC and the EACH (European Association for Children in Hospitals) charter into 10 articles, which are operational for clinical use. This review aims to discuss each of these articles and how they are applied in clinical practice.
\end{abstract}

\section{Keywords}

Pediatric anesthesia; Human rights; Children; Perioperative care; Quality of health care; Safety

\section{Introduction}

Anesthesiologists who care for children must respect the human rights of the child. Although national legislation may vary from country to country, the human rights are universal. The purpose of this article is to give a brief introduction to the human rights of the child and to review how they are applied in everyday clinical practice. The grounds for the discussion are the UNCRC (Fig. 1), the EACH charter and the 10 rights of children undergoing anesthesia as defined by the SAFETOTS initiative [1-3].

The UNCRC, adopted for signature in 1989, and as of today ratified by all United Nations (UN) members except the United States of America (USA), lays out the foundation for the human rights for individuals under the age of 18 years. $\mathrm{UN}$ member states who have ratified the UNCRC, are bound by international law to work to implement and respect the UNCRC in national legislation and must continuously report back to the UN on the progress hereof. Four articles of the UNCRC are recognized as special and instrumental in how the rest of the UNCRC is realized.

The articles comprise Article 2: Non-discrimination, article 3: Best interest of the child, Article 6: Right to life survival and development, and article 12: Right to be heard. Article 24 of the UNCRC concerns the child's right to healthcare and declares the following: "States Parties recognize the right of the child to the enjoyment of the highest attainable standard of health and facilities for the treatment of illness and rehabilitation of health", meaning that healthcare workers and healthcare institution at any given time must aspire to provide facilities and care to children in a manner universally recognized as the "highest attainable standard", whatever that may be.

In 1988 , in the city of Leiden, a charter, later known as the EACH charter was formulated to set the standards on how children are cared for when hospitalized. The charter endorses the UNCRC and is today widely recognized as a European standard on child and parental rights when admitted to hospitals. The charter comprises 10 articles in which the human rights of the child are translated into the setting of a hospital. The EACH charter is more specific on how human rights apply to children, and their parents, when they are admitted to hospital, and addresses, among the following issues, how and when a child should be admitted to hospital, how it should be accommodated, how it should be informed, how it should be cared for and that it should never be admitted in an adult ward. Health-care workers, parents, guardians, and others who are involved in caring for children in healthcare facilities are obliged to act according to the UNCRC principles.

Hence this also applies to anesthesiologists when undertaking the care of children in the perioperative setting.

\section{The SAFETOTS rights}

The SAFETOTS initiative, founded by a group of anesthesiologists to promote safe pediatric anesthesia, has defined a set of standards on how to practice this. SAFETOTS asks the questions who, where, when, and how pediatric anesthesia should be conducted in clinical practice. Among these standards, SAFETOTS has defined the rights of the child undergoing anesthesia, translating the UNCRC and EACH charter into 10 articles that apply to clinicians who conduct pediatric anesthesia.

In the following, we will discuss each of these 10 rights on how they are adopted and applied into everyday clinical practice. 


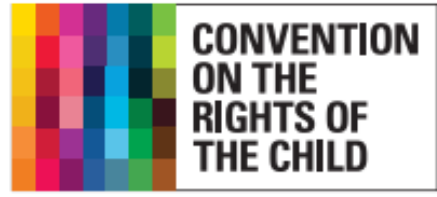

\section{THE UNITED NATIONS CONVENTION ON THE RIGHTS OF THE CHILD - THE CHILDREN'S VERSION}

\author{
The United Nations Convention \\ on the Rights of the Child is an \\ important agreement by countries \\ who have promised to protect \\ children's rights. \\ The Convention on the Rights of \\ the Child explains who children \\ are, all their rights, and the \\ responsibilities of governments. \\ All the rights are connected, \\ they are all equally important \\ and they cannot be taken away \\ from children.
}

This text is supported by the Committee on the Rights of the Child.

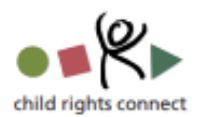

\section{$\frac{\text { unicef (s) }}{\text { for every child }}$}

F I G RE 1. The United Nations Convention on the Rights of the Child (child-friendly version). Published with Permission from the UN. For more details please visit: https://resourcecentre. savethechildren.net/ node/15932/pdf/UNICEF \%202019\%20 convention \%20 on\% 20the $\% 20$ rights $\% 20$ of $\% 20$ the $\% 20$ chid.pdf.

\subsection{Right to enjoy the highest attainable standard of health}

Children are not just small adults. They are different in respect to anatomy, physiology, and neurocognitive behavior. Hence this mandates special knowledge and a different approach to a child compared to the adult patient. The "APRICOT" study on adverse events in pediatric anesthesia found a higher incidence of airway and cardiovascular events when pediatric anesthesia was undertaken by less experienced staff [4]. A fact that has long been recognized in the pediatric anesthesia community, and hence there have long been strong arguments recommending special education and experience, especially in the undertaking of neonatal and infant anesthesia [5]. More European countries today offer fellowships in pediatric anesthesia of 1-2 years duration. An example hereof is the Scandinavian Society of Anesthesia and Intensive Care (SSAI) 2 years fellowship, consisting of clinical, academic courses and an abroad exchange program [6]. SAFETOTS recommend that anesthesia for children less than 3 years, ASA (American Society of Anesthesiologist) physical status class 3 or above, or anesthesia for major surgery is undertaken by an anesthesiologist with special training and that pediatric anesthesia is only carried out in dedicated children's hospitals or larger hospital with pediatric wards.

The Royal College of Anesthetists (RCoA) have in their latest edition on "Guidelines for the provision of pediatric anesthetic services 2020" a detailed description of the competencies required and the facilities needed for conducting safe pediatric anesthesia and is an example of how a national scientific society makes recommendations in line with the recommendations above [7].

In the future, we will hopefully see more educational programs in pediatric anesthesia around the globe, including developing countries as a means of reducing perioperative child mortality and morbidity [8].

\subsection{Rights to non-discrimination}

Children have the right not to be discriminated against on basis of race, religion, sex, ability, whatever they think or say, or whatever family they come from. Healthcare workers should not be influenced by differences of the above standing. Cultural differences, language problems, and religious beliefs can undoubtedly pose a challenge to the clinician in his/her approach to the patients. A recent survey from the U.S. showed that children of African American ethnicity were 3.5 times more likely to die 30 days after surgery, $18 \%$ relative greater odds of developing postoperative complications, and $7 \%$ relative greater odds of developing serious adverse events compared to white Americans [9]. The apparent racial disparity could not be explained by differences in preoperative physical status, and although the authors do not conclude that racial discrimination is a direct cause, one can speculate about how low social status, different educational level, and religious belief as contributing factors in how healthcare workers interact in the caring of this group of patients. Other studies have likewise shown racial disparities in the outcome between patients of a different races [10].

It is therefore important that clinicians prepare for these probable challenges beforehand. Knowledge of cultures, religions, and regional habits, together with the help from persons with resources and knowledge could help the clinician.

\subsection{Right to be protected from economic exploitation}

Anesthesia for children should always be of "the highest attainable standard" and hospitals and/or private practices should not speculate economically, for instance, by saving money on staff, equipment and/or physical facilities that may result in a lower standard of care as generally accepted. A French survey has shown that, although practices in general are homogenous, anesthesiologist in private practices were less likely to insert an intravenous line during general anesthesia and less likely to use an airway device during adenoidectomy [11]. A highly educated staff, special equipment and interior design of a clinic can be costly for smaller private practices. This should, 
however, not prompt a lower standard, but rather letting a more suitable clinic do pediatric cases.

\subsection{Right to be protected from unnecessary and investigations and treatment}

There should always be a purpose for investigation and treatment, and it should always be in the best interest of the child. Unnecessary surgical procedures that risk leaving the child permanently disabled should always be carefully considered and at best discussed in multidisciplinary teams. Radiological procedures that risk exposure to radiation should be outweighed in favor of less risky procedures that could yield the same information. Surgical procedures where anesthesia bears a high degree of risk (neonates, critically ill, cardiac patients) should always be carefully considered in terms of outcome, timing, and competencies. Just as well as clinicians need to contemplate the necessity of specific procedures and outweigh the risk, they should avoid pressure from parents/guardians demanding various procedures, which from a professional viewpoint is not indicated or bears a higher risk than the possible outcome.

\subsection{Right to avoid pain, fear, and stress}

A cornerstone of pediatric anesthesia is the treatment of pain, fear, and stress and seems so inherent in the competencies of the pediatric anesthesiologist. However, pain and fear are often inadequately treated. Assessing pain, fear, and stress in children can be challenging for the anesthesiologist and requires pain management tools that are age-specific and postoperative care facilities staffed with nurses educated in pediatric pain management. Preoperative fear in children undergoing anesthesia is a common problem and is sometimes impossible to avoid. However, there are various methods to reduce anxiety and stress preoperatively. Among these tools are a variety of pharmacological and non-pharmacological approaches [12, 13]. Restraining children physically should as such be avoided, although the ambiguity of clinicians' perception of the term exists [14].

\subsection{Right to have their parents with them}

Children should be allowed to be accompanied by a parent/parents in the operating room (OR). Although studies are conflicting, in regard to reducing anxiety of the child, the satisfaction of parents and of doctors after implementation of parents in the OR are of great significance [15-17]. Separating the child from its parents before induction of anesthesia can be of great stress to both parties and should be avoided, although the stress of induction of anesthesia may not be altered. We believe that parental presence is of great significance not only for the child, but also the parents and should always be allowed. Besides reducing the stress of separation, it could also build trust between parents and the anesthesia team, when the parents themselves can witness that their child are cared for with respect and competence. Concerns that parental presence should increase OR times is ungrounded [18].

\subsection{Right to privacy}

The privacy of the child should be respected during, under, and after surgery/anesthesia. A child should not be unnecessarily exposed during surgery/examination.

\subsection{Right to be informed}

Children and their parents have the right to be informed about their condition and their treatment. The information should be age-appropriate and in a language they understand. Information should not be damaging. There are many levels where information can be provided to the child. This can either be conveyed orally at the preoperative evaluation or in written form, or both. Video material or comic book are other measures to provide the child and parents information about the upcoming procedure [19].

Besides of giving information about procedures, information also serves to reduce unnecessary anxiety and to explain things that are common and normal to the anesthesiology staff, but uncommon/unknown to the child and its parents. The information also serves as the basis for the parent/guardian to give his/her informed consent on behalf of the child.

\subsection{Right to be heard}

Just as children have the right to be informed about anesthetic procedures, they also have the right to speak out their opinion. That could be a child having an opinion on induction either with inhalation or intravenously. No matter the child's opinion can be fulfilled or not he/she has the right to be heard and respected. An example could be a child having an opinion on how induction of anesthesia should be. Should it be inhalational induction or intravenous? The child might only base his/her preference on an emotional conception but have an opinion. Children who have tried it several times might be clearer about what he/she wants. The anesthesiologist should be open-minded towards the opinions of the child but should also be wary of promising things he/she cannot keep.

\subsection{Right to be cared for together with children who have the same developmental needs}

Children have the right to be cared for in an environment together with children of the same developmental level. For instance, neonates are cared in a neonatal care unit, adolescents in another, and so forth. Surgical units organized for children and not mixed with adult surgical patients. Recovery rooms must be furnished in a child-friendly manner and a child should not be placed together with adult patients. Being in an environment with children of the same age and development stage makes the child feel it is a part of a group that it can relate to. Parents have opportunity to talk with parents who also have a sick child and create a small community.

\section{Applying the rights of the child in clinical situations}

The anesthesiologist must respect all the child's rights, but depending on the situation, fulfilling all of them in the manner 
described above can be difficult. One principle must always be fulfilled. Always do "what is best for the child". This principle applies to both clinicians, parents, governments, and so forth. It is instrumental in how the rest of the rights are applied in different situations. The parent(s)/guardian(s), who legally possesses the right to give informed consent to examinations and treatments, must also make choices by the principle "what is best for the child". Hence the clinician and parent work together to make these choices.

In 2 case-stories we will try to illustrate how the rights of the child are applied:

Case 1.

An 8-year-old girl, without prior diseases, presents for tooth extraction and a dental filling in general anesthesia. The procedure has been scheduled months ahead. Preoperative evaluation and information about general anesthesia is undertaken by the dentist, which is normal standard of care, and the information conveyed to the anesthesiologist in charge. They have received EMLA (Eutectic Mixture of Local Anesthetics) plaster by mail including instructions for use and the plaster is applied correctly 2 hours before the surgical procedure. The girl is in a good mood and shows no sign of anxiety up until she enters the operating theatre. When faced with the anesthesia team she suddenly refuses to corporate and bursts into tears and now shows signs of anxiety. She cannot be persuaded to sit in the dentist chair and just stands in the corner of the theatre. The girl's father, who accompanies her together with the girl's mother, chooses to drag her to the chair, and with her screaming the anesthesia nurse applies the mask to her face with force. She is quickly anesthetized with sevoflurane and the surgical procedure is carried out without complications. Later when recovering from anesthesia, she appears calm. The parents talked to the girl about what had happened, and she seemed afterward to be ok.

In this case, the procedure went through with the girl being forced under circumstances where she suffered a short, but intense bout of anxiety and stress. No matter what, the best interest of the child was to get the tooth extracted and the dental filling is done. However, none of these two procedures needed to be done straight away. They could have waited, either until later the same day or another day. In waiting, preparations could have been made to reduce the anxiety and stress and avoid restraining the girl on the next occasion. A preoperative sedative, e.g. midazolam or an alpha 2 antagonist, could have been prescribed. So, in this case, the parents and the anesthesia staff could have done better to reduce anxiety and stress, and the information on the procedure could also have been better.

Case 2.

An 11-year-old boy presents to the emergency department of a larger hospital with clinical signs of appendicitis. He is transferred to the pediatric surgical ward in waiting for a laparoscopic appendectomy later the same day. Unfortunately, surgery is not possible straight away and during the waiting time, his condition deteriorates due to perforation of the appendix. He has an intravenous (IV) line inserted, with difficulty, and is rushed to surgery as soon as the previous procedure has finished. Unfortunately, the iv-line is displaced during his transfer from the bed to the operating table, and the anesthetist chooses to do an inhalational induction. The boy only receives sparse information. IV cannulation is difficult, but after several attempts, finally successful and he is resuscitated with lactated Ringer's solution. The appendix is removed, and the abdomen cleared for pus. After a couple of days on IV antibiotics, he recovers.

Are the boy's rights violated? The boy quickly develops critical illness after admission and needs emergency surgery. There is no time to inform about the anesthetic procedure and action must be taken immediately. He gets no chance to speak his mind because surgery was imminent. In this case, the boy's rights were not violated because the principle of doing "what is in the child's best interest" had to be carried out quickly on the cost of preoperative information and letting him speak out his own opinion.

\section{Conclusions}

Respecting the rights of the child in healthcare is mandatory for every healthcare worker working with children. The SAFETOTS initiative has translated the UNCRC and EACH charter into 10 applicable articles concerning children undergoing anesthesia. The anesthesiologist should always seek to respect all these 10 articles, but must, first of all, do "what is the best for the child". Not meaning that the 10 articles can be set aside when it seems suitable, but only when respecting one or more articles objectively can hinder doing "what is best for the child". This of course requires high ethical standards of the anesthesiologist.

\section{ABBREVIATIONS}

ASA, American Society of Anesthesiologists; EACH, European Association for Children in Hospital; EMLA, Eutectic Mixture of Local Anesthetics; IV, Intravenous; OR, Operating Room; RCoA, Royal College of Anaesthetists; SAFETOTS, Safe Anesthesia for Every Tot; UNCRC, The United Nations Convention of the rights of the child; USA, United States of America.

\section{AUTHOR CONTRIBUTIONS}

Both authors contributed equally.

\section{ACKNOWLEDGMENT}

I would like to express my gratitude to all those who helped me during the writing of this manuscript.

\section{CONFLICT OF INTEREST}

The authors declare no conflict of interest.

\section{REFERENCES}

[1] MacPherson S. The convention on the rights of the child. Social Policy \& Administration. 1989; 23: 99-101.

[2] EACH European Association for Children in Hospital.The 10 articles of the EACH Charter. 2016. Available at: https://www.each-for- 
sick-children.org/each-charter/the-10-articles-ofthe-each-charter (Accessed: 16 January 2021).

[3] Weiss M, Vutskits L, Hansen TG, Engelhardt T. Safe Anesthesia for every Tot - the SAFETOTS initiative. Current Opinion in Anaesthesiology. 2015; 28: 302-307.

[4] Habre W, Disma N, Virag K, Becke K, Hansen TG, Jöhr M, et al. Incidence of severe critical events in paediatric anaesthesia (APRICOT): a prospective multicentre observational study in 261 hospitals in Europe. The Lancet Respiratory Medicine. 2017; 5: 412-425.

[5] Weiss M, Hansen TG, Engelhardt T. Ensuring safe anaesthesia for neonates, infants and young children: what really matters. Archives of Disease in Childhood. 2016; 101: 650-652.

[6] SSAI. Paediatric anaesthesia and intensive care. 2015. Available at: https://ssai.info/education/paediatric-anaesthesia/ (Accessed: 09 January 2021).

[7] Royal College of Anaesthetist. Guidelines for the provision of paediatric anaesthesia services. 2020. Available at: https : / rcoa.ac.uk/gpas/ chapter-10 (Accessed: 10 December 2020).

[8] Gonzalez LP, Pignaton W, Kusano PS, Módolo NSP, Braz JRC, Braz LG. Anesthesia-related mortality in pediatric patients: a systematic review. Clinics. 2012; 67: 381-387.

[9] Nafiu OO, Mpody C, Kim SS, Uffman JC, Tobias JD. Race, postoperative complications, and death in apparently healthy children. Pediatrics. 2020; 146: e20194113.

[10] Goyal MK, Kuppermann N, Cleary SD, Teach SJ, Chamberlain JM. Racial disparities in pain management of children with appendicitis in emergency departments. JAMA Pediatrics. 2015; 169: 996-1002.

[11] Constant I, Louvet N, Guye ML, Sabourdin N. Anesthésie générale chez l'enfant: quid des pratiques en 2010? General anaesthesia in children: a French survey of practices. Annales Françaises d'Anesthésie et de Réanimation. 2012; 31: 709-723. (In French)

[12] Perry JN, Hooper VD, Masiongale J. Reduction of preoperative anxiety in pediatric surgery patients using age-appropriate teaching interventions.
Journal of Perianesthesia Nursing. 2012; 27: 69-81.

[13] Fortier MA, Kain ZN. Treating perioperative anxiety and pain in children: a tailored and innovative approach. Paediatric Anaesthesia. 2015; 25: 2735.

[14] Homer JR, Bass S. Physically restraining children for induction of general anesthesia: survey of consultant pediatric anesthetists. Paediatric Anaesthesia. 2010; 20: 638-646.

[15] Chundamala J, Wright JG, Kemp SM. An evidence-based review of parental presence during anesthesia induction and parent/child anxiety. Canadian Journal of Anesthesia. 2009; 56: 57-70.

[16] Sadeghi A, Khaleghnejad Tabari A, Mahdavi A, Salarian S, Razavi SS Impact of parental presence during induction of anesthesia on anxiety level among pediatric patients and their parents: a randomized clinical trial. Neuropsychiatric Disease and Treatment. 2017; 12: 3237-3241.

[17] Erhaze EK, Dowling M, Devane D. Parental presence at anaesthesia induction: a systematic review. International Journal of Nursing Practice. 2016; 22: 397-407.

[18] Moseley SL, Heine C, Valente T, Stone D, Levy DA, Downs JB, et al. Effects of parental presence during induction of anesthesia on operative and perioperative times in pediatric patients undergoing adenotonsillectomy. International Journal of Pediatric Otorhinolaryngology. 2021; 140: 110515 .

[19] Kassai B, Rabilloud M, Dantony E, Grousson S, Revol O, Malik S, et al. Introduction of a paediatric anaesthesia comic information leaflet reduced preoperative anxiety in children. British Journal of Anaesthesia. 2016; 117: $95-102$.

How to cite this article: Kristian Noerholm Jensen, Tom Giedsing Hansen. Children undergoing anaesthesia: what are the rights of the child? Signa Vitae. 2021;17(4):203-207. doi: $10.22514 /$ sv.2021.059. 